\title{
An Innovation Platform for Diffusing Public Health Practices across a Global Network
}

\author{
Alexander Plum \\ Henry Ford Health System \\ aplum2@hfhs.org
}

\author{
Mohan Tanniru \\ Henry Ford Health System \\ mtannir1@hfhs.org
}

\author{
Jiban Khuntia \\ University of Colorado Denver \\ jiban.khuntia@ucdenver.edu
}

\begin{abstract}
Hospitals and health systems in high-income countries (HIC) develop the capacities of peer healthcare organizations around the world by diffusing clinical, quality, and public health improvement practices in lower and middle-income countries (LMIC). In turn, these HIC healthcare institutions are exposed to innovative approaches developed and used by global communities to advance care despite resource constraints in the LMIC contexts. Attention has been growing in recent years to the potential these innovations can have to improve care delivery, lower costs, and drive quality within resource constrained communities in HIC. Often referred to as 'reverse innovations,' the identification, adaptation, and diffusion of these practices face challenges in uptake related to limited evidence, perceptions of poor quality or irrelevance, and a complicated regulatory and policy environment. This paper suggests the development of a knowledge platform to support diffusion of innovative health practices along a global community continuum and illustrates its potential use.
\end{abstract}

\section{Introduction}

Hospitals and health care systems in the United States are increasingly becoming engaged with their peer institutions around the world. As a result, learning is taking place between organizations that results in new opportunities, organizational growth, increased job satisfaction, better market position, improved brand recognition, and, most importantly, better health care provision for patients and communities alike.

At the core of these hospital and health system partnerships are opportunities for reciprocal exchange of ideas, approaches, and expertise. Often referred to as international health partnerships, examples in the literature include collaborative trainings, research activities, capacity development, and service delivery [1]. Determining how to move medicine to places where there are logistical challenges, how to educate a diverse array of caregivers in professional and lay contexts, how to build the capacity of medical researchers, and how to leverage social support structures to overcome stigma about medical conditions are only a handful of examples that demonstrate innovation flow from high-income countries (HIC) to low- and middle-income countries (LMIC), a process we refer to as 'high-low innovation.' Figure 1 illustrates the role of an HIC healthcare institution in moving innovations in this direction using a number of diffusion strategies.

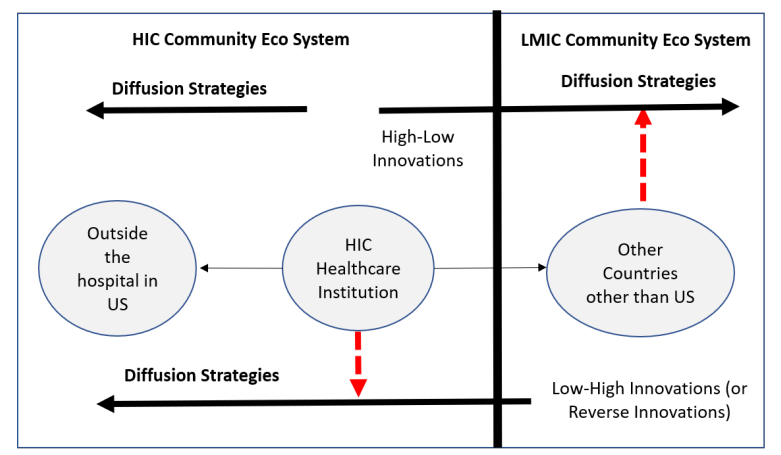

Figure 1: Innovation and Diffusion Strategies

The flow of innovations in the opposite direction is still nascent in healthcare. In this direction, HIC healthcare institutions discover certain medical and non-medical innovations that are used in LMIC to address the unique healthcare needs of communities with significant resource constraints. Examples of these innovations include community healthcare workforces to arrest HIV rates, support pregnant mothers, and improve mental health outcomes [2, 3]; mobile applications to facilitate cash transfers to help pay for medical care and better collect and analyze data $[4,5]$; and devices and products that can quickly identify disease and support treatment [6, 7]. Indigenously developed in LMIC contexts to overcome specific community challenges and resource constraints, these innovations are potentially applicable to other regions with similar scarcity characteristics, 
including cities and regions in HIC such as the United States. Water contamination issues in Flint, Michigan over the past several years provides an example for the potential application of water filters for cleaner water in a similar resource-limited, HIC setting. These 'lowhigh innovations' are often referred as 'reverse innovations' and are shown in the lower part of the left-hand block of Figure 1.

The goal of this paper is to develop effective mechanisms to explore the viability and facilitate the diffusion of innovations that flow in both 'high-low' and 'low-high' directions, specifically from the perspective of an HIC healthcare institution. Diffusion, at its core, is a social phenomenon that is informed by the interconnectedness of actors involved in an innovation's design, testing, communication, and, eventually, uptake [8]. Because it is a social process, innovation adoption is informed by the social and structural positions in which innovation disseminators and potential adopters respectively find themselves [9, 10]. Thus, perceptions of credibility and effectiveness, along with trust and deference matter as much on the part of innovators and adopters as on the innovations themselves. Social positions and attendant hierarchies of innovators and adopters alike inform how well innovations can be diffused.

Nowhere is this more apparent than in the disparity in innovation diffusion between 'high-low' and 'low-high' contexts. While the high-low path of innovation has been a widely accepted expectation and norm (thus, without significant barriers), challenges to 'low-high' diffusion have included regulation hurdles, legal barriers, and stigmas based on negative perceptions regarding source location, adherence to quality standards, and relevance or applicability in HIC $[11,12]$. In fact, even the name used most often in the literature to refer to 'low-high' innovations (i.e. 'reverse innovation') implies a negative connotation that many, including these authors, find problematic [12].

Indeed, this diffusion disparity is reflected through the lowest-shelf placement of use-and-throw shaving razors and the relegation of sachet-shampoo in big-box stores to the travel-size and sample bins. In comparison to pricey and branded products, these 'good enough' products are considered 'cheap' and 'lackluster.' Such perceptions and connotations lead to feelings of disenchantment and rejection for low-high innovations. The research question, therefore, is especially concerned with developing an approach that addresses challenges associated with diffusion of innovations within low-high contexts, while keeping intact the underlying integrity and value of the innovations across the adoption process and engaged societal contexts. The paper is organized as follows:
Section Two discusses diffusion theory and highlights a specific approach called 'design for diffusion.' Sections Three and Four describe a case study to demonstrate how this approach has facilitated the successful diffusion of two innovations within a low-high context. Based on this experience, Section Five proposes a generalizable platform to support the bidirectional flow of innovations for diffusion in both high-low and low-high contexts. Section Six provides some concluding comments and directions for future research.

\section{Prior research}

Diffusion theory has been well-documented in the literature. Beginning with Everett Rogers' seminal work in 1962, researchers have applied and revised his tenets that inform how and whether an innovation will diffuse across domains and fields of interest [13]. Rogers and scholars that followed him cite common innovation attributes that either facilitate or prevent diffusion from occurring. These include an innovation's compatibility to existing approaches, costs of success or failure, simplicity to adopt, potential effectiveness, whether effectiveness has been or can be observed, and the ease with which innovations can be informally trialed [8]. The dynamics of innovation diffusion in the healthcare industry are complex. New medical and information technologies often follow a slow pace of adoption in healthcare, and the speed at which diffusion occurs is also slow. The number of stakeholders in healthcare potentially affected by a technology adoption decision varies. For example, a clinician has to consider reimbursement, policy, and organizational models beyond the impact of a technology on patient and practice of care. Rogers' change agent factor, i.e., an individual who influences clients' innovation decisions in a direction deemed desirable by an agency, is predominant in the healthcare sector, where almost 60,000 pharmaceutical sales representatives, as change agents, influence innovation decisions. Thus, arguably, within healthcare, it is pointed out that diffusion often occurs because of intentional dissemination activities, not the strength of evidence alone [8].

For resource-constrained populations seeking high quality health outcomes, there are additional challenges for innovation diffusion and uptake besides intention to adopt or strength of evidence. In these environments, individuals often cannot afford to pay high sums to achieve the desired outcomes. In settings where infrastructure and onerous regulation are either underdeveloped or absent, the environment is prime for creating product and technology innovations to 
facilitate training, education, quality healthcare delivery, data collection, logistics management, and workforce deployment. In these settings, innovations must apply to broad populations for economies of scale to achieve profitability, and the chosen diffusion models must help address a challenging environment or organizational context to nurture a creative, sustainable solution to achieve health and wellness.

Understanding the contexts within which these scarcity-informed innovations are developed is a necessary precursor to describing and eventually winning support for diffusion. The term reverse innovation (RI) was coined to describe the flow of innovative ideas from lower to higher income settings [14]. As applied to healthcare, DePasse and Lee define reverse innovation as "learning from and investing in poorer settings as one way to tackle problems in wealthier settings that require out-of-the-box solutions" [15]. (Note: when the authors refer to 'out-of-the-box' they mean it in the sense of approaches that break the mold and are new and innovative, not in the sense of a pre-packaged, boxed ideas.) The secret to a reverse innovation paradigm shift is to look for "value for many" instead of "value for money" [16]. Rising healthcare costs, insufficient insurance coverage, inefficient public transportation, health illiteracy, and a lack of trust in the health system are only a few of the many factors that require a new paradigm for healthcare innovations in the US and other HICs.

The literature on innovation diffusion theory is overwhelmingly source agnostic, which complicates the study of low-high innovation diffusion. Dearing and colleagues offer one theoretical platform that may be a useful starting point for exploring and explaining the differences in how to diffuse innovations in both 'high-low' and 'low-high' directions: designing for diffusion [8]. "Designing for diffusion is the taking of strategic steps early in the process of creating and refining an evidence-based intervention to increase its chances of being noticed, positively perceived, accessed, and tried and then adopted, implemented, and sustained in practice" [8]. Using Dearing et. al.'s designing for diffusion approach, the authors aim to explore the research question by examining a case study of an HIC healthcare institution that has successfully facilitated bidirectional global innovation flow.

\section{Research methodology}

Henry Ford Health System (HFHS), headquartered in Detroit, Michigan, is a leading US healthcare provider, comprised of hospitals, medical centers, a health plan, and one of the nation's largest group practices, the Henry Ford Medical Group. The Henry Ford Global Health Initiative (GHI) works with healthcare partners in LMIC around the world to co-develop medical capacity through training, research, and exchange activities. Over time, as its program relationships deepen, GHI learns about the innovative solutions its partners and local communities use to deliver healthcare services, deploy new workforces, sustainably finance care, and share and analyze information. Especially promising innovations are identified and vetted for future adaptation and pilot in Detroit, to improve the health of underserved populations at home. This reciprocal innovation flow of high-low capacity development and low-high 'reverse innovation' defines GHI's approach to achieving equitable global health development and serves as an enduring model of transformative partnerships in healthcare.

We follow the case study methodology to illustrate how the design for diffusion approach can help structure the activities of GHI over the last few years. Creswell et. al. [17] define the case study method as "a qualitative approach in which the investigator explores a bounded system (a case)... over time through detailed, in-depth data collection involving multiple sources of information (e.g., observations, interviews, audiovisual material, and documents and reports) and reports a case description and case-based themes" [17]. Over the course of 18 months, the authors systematically categorized and refined the types of 'high-low' and 'low-high' innovations being shared. Interviews were conducted with leaders at the HIC institution, their respective LMIC partner institution stakeholders and innovators, global thought leaders in the nascent field of 'reverse' innovation, and quality improvement advisers from leading healthcare institutions in the US.

Table 1 describes the interviews, timeline, and themes explored. In-depth notes from interviews were taken and shared among the authors, who spent three months surfacing themes, reconciling interpretations, and drawing conclusions. Extant evaluation data of the case study institution's programs were reviewed and analyzed to build the case description and surface themes. Using the principles of grounded theory and thematic analysis, the authors developed various diffusion methods that evolved in their practice, and this is discussed next.

Table 1: Representative Summary of Field Level Interactions and Sources

\begin{tabular}{|c|c|c|}
\hline Interviewees & \begin{tabular}{|l|}
$\begin{array}{l}\text { Total hours spent in every } \\
\text { year for direct interview \& } \\
\text { unstructured interactions }\end{array}$ \\
$2014|2015| 20|6| 2017$
\end{tabular} & Interview Themes \\
\hline
\end{tabular}




\begin{tabular}{|l|c|c|c|c|c|l|}
\hline $\begin{array}{l}\text { Chief Executive } \\
\text { Officer }\end{array}$ & 3 & & & & & $\begin{array}{l}\text { Broad vision, strategy, and leadership } \\
\text { contexts; overarching opportunity for } \\
\text { global health leadership }\end{array}$ \\
\hline $\begin{array}{l}\text { CEO of Medical } \\
\text { Group }\end{array}$ & & 2 & 2 & 2 & 2 & $\begin{array}{l}\text { Role of medical training and research } \\
\text { exchange to inform global health } \\
\text { leadership }\end{array}$ \\
\hline $\begin{array}{l}\text { President of } \\
\text { Healthcare } \\
\text { Operations }\end{array}$ & & & & 3 & 3 & $\begin{array}{l}\text { Value proposition and alignment with } \\
\text { service lines to maximize return on } \\
\text { investment. }\end{array}$ \\
\hline $\begin{array}{l}\text { Chief Innovation } \\
\text { Officer }\end{array}$ & & 3 & 3 & 3 & 2 & $\begin{array}{l}\text { Role of technology and digital } \\
\text { innovations to support business case }\end{array}$ \\
\hline $\begin{array}{l}\text { Chief Wellness \& } \\
\text { Diversity Officer }\end{array}$ & & 6 & 4 & 8 & 7 & $\begin{array}{l}\text { Underserved communities; opportunities } \\
\text { for local impact, engagement, and a } \\
\text { focus on equity }\end{array}$ \\
\hline $\begin{array}{l}\text { SVP, Population } \\
\text { Health }\end{array}$ & & & & 2 & 8 & $\begin{array}{l}\text { Value-based and risk-based models to } \\
\text { structure and facilitate tests of change }\end{array}$ \\
\hline $\begin{array}{l}\text { Clinical staff, nurse } \\
\text { managers }\end{array}$ & 8 & 8 & 6 & 8 & 10 & $\begin{array}{l}\text { Workflows, opportunities to achieve } \\
\text { efficiency, scope of practice concerns, } \\
\text { barriers, passion \& satisfaction }\end{array}$ \\
\hline $\begin{array}{l}\text { Patients \& } \\
\text { consumers (n=40) }\end{array}$ & 10 & 10 & 10 & 10 & 10 & $\begin{array}{l}\text { Social determinants of health; local } \\
\text { context; barriers to accessing healthcare }\end{array}$ \\
\hline $\begin{array}{l}\text { Community-based } \\
\text { organizations } \\
\text { n=12) }\end{array}$ & & 6 & 10 & 12 & 10 & $\begin{array}{l}\text { Network \& collaboration opportunities; } \\
\text { efforts to achieve complementarity in } \\
\text { service provision }\end{array}$ \\
\hline
\end{tabular}

Dearing et al's design of diffusion process has four phases [8]. The first, agenda-setting and assessing readiness, begins before GHI engages its partners. For 'high-low' innovations, these are long-time and newly identified partners in the ministry of health, universities, health systems, and non-governmental organizations (NGO) in LMIC. For 'low-high' innovations, these are internal health system department leaders and clinicians, as well as local and regional community partners. A year-long strategy alignment process within HFHS led GHI to identify five priority health topics with relevance to the health system, to Detroit, and to the entire world. After conducting structured in-depth interviews and focus group conversations with patients, health system leadership, and community representatives, and a serious review of the literature, five priority topics emerged: infant and maternal health, mental health, metabolic health, sexual and reproductive health, and stewardship of antibiotics. Only after categorizing its strengths and expertise, and contextualizing these with an acute awareness of its weaknesses, did GHI approach its partners to learn their needs and receive direction in how best to co-develop capacity and/or import innovative solutions.

The second design for diffusion step is dissemination and distribution. Using inductive methods, GHI categorized the public health practices it has used globally into six types of innovations, in alignment with WHO's building blocks of health systems [18]: Healthcare service delivery innovations to train medical institutions and local communities in improvement of preventive and secondary medical care delivery; workforce innovations, such as deploying alternative workforces and/or training clinicians with research skills to better collect, analyze, and diffuse data and care practices; health information innovations, which include the technology and data collection and analysis applications to track and monitor health outcomes; product innovations, which include the vaccines, devices, and technologies used to facilitate healthcare delivery and improvement; health financing innovations that ensure sustainable health care delivery through payment and reimbursement mechanisms; and policy innovations, including rules, regulations, policies, and standard operating procedures to improve quality and efficiency of care. These six innovation types represent a starting point from which GHI's partners can identify opportunities for innovation flow to occur. Table 2 includes examples of communityexpressed goals (i.e. phase one: agenda setting) and the relevant types of innovations selected for pilot projects for diffusion (i.e. phase two: dissemination and distribution).

\section{Table 2. Examples of Paired Community Needs to} Innovation Types

\begin{tabular}{|l|l|}
\hline Community Goal & Innovation Model \\
\hline $\begin{array}{l}\text { Reduce overall time to train } \\
\text { medical specialists }\end{array}$ & $\begin{array}{l}\text { Process innovation: Introduce } \\
\text { specialist surgical 'boot camp' training } \\
\text { model }\end{array}$ \\
\hline $\begin{array}{l}\text { Improve research skills and } \\
\text { increase publications of early- } \\
\text { and mid-stage medical staff }\end{array}$ & $\begin{array}{l}\text { Practice innovation: Jointly created } \\
\text { mixed-methods research design \& } \\
\text { training in-service short-course for } \\
\text { hospital staff }\end{array}$ \\
\hline $\begin{array}{l}\text { Maintain strict adherence to } \\
\text { existing laws and prevent } \\
\text { public smoking/tobacco use }\end{array}$ & $\begin{array}{l}\text { Policy innovation: Public advocacy } \\
\text { campaign and engagement with senior } \\
\text { management to obtain support }\end{array}$ \\
\hline
\end{tabular}

The examples listed in Table 2 must be further contextualized and refined by the characteristics of the stakeholders whose engagement and acceptance will define their diffusion. Such contextualization can be based on diffusion strategies discussed earlier [12] (e.g. evidence, trialability, simplicity, etc.), as well as several other factors, such as adopter behavior, innovation type, and relative advantage. Consideration of these factors constitutes Dearing et al's third phase, which consists of engaging and winning over influential stakeholders, gatekeepers, and community representatives "whose trustworthiness and expertise serve as social confirmation" that an innovation can be successfully adopted [8]. As noted earlier, diffusion is a social process, which means that the beliefs, perceptions, and prejudices of adopters and innovators alike converge to inform whether or not innovations will even be selected for pilot and/or adaptation, let alone fully diffused. This seldom prevents GHI's 'high-low' innovation diffusion from occurring successfully, but it has been a continual barrier to successful 'low-high' innovation flow.

Only by convincing decision-makers and key influencers of these innovations' merits can GHI move on to Dearing et al's fourth and final phase of diffusion 
design, which is implementation into practice settings. GHI has undertaken two such implementations over the last two years - providing access to mental health care and supporting access to care for homeless, young LGBTQ individuals, and these will be discussed in the next section.

\section{Results}

\subsection{Mental Health Prevention}

Providing access to mental healthcare to populations in Detroit is challenging because many patients lack transportation, do not have a single point of contact with behavioral health or psychiatry services, mistrust the health system, and are under- or uninsured. Poor reimbursement levels and high appointment cancellation rates also lead to waiting lists that last several months, which can deter patients and reinforce the high price of mental healthcare.

One of GHI's long-term partners in a South Asian LMIC identified an approach it used to construct healthcare infrastructure in a sparsely populated, rugged, mountainous setting. Their setting required innovative approaches to maximize reach (i.e. decentralize the workforce), while minimizing costs (i.e. centralize capital and infrastructure). A service delivery innovation called 'hub and spoke' guided the establishment of health outposts in informal settings like temples, schools, and municipal offices, which all became spokes that were connected back to a central 'hub' hospital. A workforce innovation was developed, whereby community health workers (CHWs) were trained and equipped at the hub and then returned to their villages to staff the spokes. Given that they were usually the first and only point of contact for remote villagers, CHWs helped improve chronic disease management, contraceptive use prevalence, and institutional births. Feedback from the CHWs revealed a need for training in mental health first aid to address contextual drivers of illness and disease [19].

GHI adapted the hub and spoke model for use in Detroit to improve mental health treatment rates among low-income adult patients of HFHS. A mental health psychotherapist was integrated within the primary care office by utilizing video technology. When patients came to see their doctor and displayed a mild to moderate mental health condition, they could see a therapist in the same location on the same day. As a follow-up, trained CHWs visited the patient at home or over the phone, depending on preference, to conduct motivational interviewing and connect the patient with resources to sustain their positive health outcomes.
This is just one illustration of how reverse innovation can improve care delivery.

Table 3. Drivers of Diffusion Models

\begin{tabular}{|l|l|l|}
\hline $\begin{array}{l}\text { Detroit } \\
\text { Nemmunity } \\
\text { Need }\end{array}$ & Innovation Model & Drivers of Diffusion \\
\hline $\begin{array}{l}\text { Access to } \\
\text { mental health } \\
\text { services }\end{array}$ & $\begin{array}{l}\text { Hub and spoke } \\
\text { service delivery } \\
\text { model }\end{array}$ & $\begin{array}{l}\text { Complementarity to existing } \\
\text { HFHS medical infrastructure; } \\
\text { promise of effectiveness to reduce } \\
\text { transportation barriers; trialability }\end{array}$ \\
\hline $\begin{array}{l}\text { Affordable } \\
\text { treatment } \\
\text { options }\end{array}$ & $\begin{array}{l}\text { CHW workforce } \\
\text { model and tele- } \\
\text { health product } \text { and } \\
\text { health information } \\
\text { model }\end{array}$ & $\begin{array}{l}\text { Low-cost and identification of } \\
\text { reimbursement mechanism for } \\
\text { both telehealth and CHWs } \\
\text { deployment; Regard for patient } \\
\text { feedback and satisfaction }\end{array}$ \\
\hline
\end{tabular}

Table 3 summarizes the core drivers that guided its use of Dearing et al's third and fourth phases to achieve diffusion of a 'low-high' innovation in Detroit.

\subsection{LGBTQ Peer Empowerment and Health Navigation}

GHI recently partnered with a Detroit-area nonprofit organization serving young, homeless, LGBTQ people. Nationally, LGBTQ identity among youth correlates with a 2.2 times increased risk for homelessness [20]. Young people in Detroit who identify themselves as LGBTQ struggle with housing insecurity, and nearly $40 \%$ are HIV positive. GHI's partnership seeks to innovatively reduce the rate of HIV incidence and increase access to testing, preexposure prophylaxis (PrEP), and education. Because of the correlation between homelessness and poor health outcomes, GHI searched innovation databases and among partners for approaches that factored in employment and income in its search. Additionally, because of the unique population being served, search criteria included marginalized and vulnerable demographic subgroups. The resultant search led to a unique solution that addressed income insecurity (as a proxy for homelessness) and limited access to HIV education, testing, and therapy. A health workforce innovation being used in a Southeast Asian LMIC was identified for adaptation and testing.

The source partner in Southeast Asia shared many of the Detroit partner's context challenges: urban density of the subject population (young, LGBTQ); experiences of stigma and rejection; broad societal recognition of LGBTQ identity; high-income insecurity; and high rates of HIV incidence. Given the similarities, conversations were initiated by GHI to discern how the Southeast Asia-based partner had recruited, hired, trained, deployed, and retained housing-insecure LGBTQ young people in community 
health worker positions to help their peers navigate their HIV care and prevention activities.

Two project initiatives have grown out of the connection facilitated via GHI between the Detroit and the Southeast Asia community organizations. First, a Detroit pilot was initiated, modeled off the peer health navigator effort, to adapt training and retention modalities among Detroit young people to serve in a similar role. Second, a community health worker exchange was developed for peer navigators in both settings to connect virtually in order to create a colocated "community of practice" exchange of cultural lessons, best practices, strategies, and support for HIV care.

In both examples, GHI started from a deep understanding of local problems. However, the two cases present slightly different approaches to identifying solutions. For mental health, GHI utilized a long-standing partner to identify the solution, while for the sexual and reproductive health case study, GHI scanned databases and external relationships to identify a promising solution.

These case studies led GHI to conclude that implementation challenges associated with diffusing such innovations as well as opportunities for identifying innovations that can support healthcare need a generalizable framework in line with supporting Dearing et al's four phases. In other words, what is needed is a source-agnostic, technology-facilitated platform capable of capturing and diffusing innovation-specific knowledge to facilitate diffusion.

In today's complex market dynamic, organizations are developing innovative products and services, often supported by information technologies, to stay effective and competitive in fulfilling their vision. To create value, these innovations must be explored at an ever-faster speed. Leading the innovation process using enabling and adaptive leadership is important, along with the administrative leadership to run the regular business [21, 22]. HFHS, with all the global communities it serves, has an extended healthcare network. GHI facilitates the "adoption" by LMIC communities of innovative public health practices generated within the US, while simultaneously "enabling" the evaluation and adaptation of ideas generated within its global community network for potential adoption in the US. To support low-high and high-low innovation dissemination, GHI needs an innovation fostering platform that helps support the coordination of multiple stakeholders in the exploration, learning, adaptation, and evaluation of both forward and reverse innovations, as it designs diffusion strategies to address global community needs. The following section proposes the development of a global health innovation platform (GHIP) to support diffusion of innovations across a global community network.

\section{Discussion}

\subsection{GHIP Model for Platform Development}

The GHIP platform captures the knowledge of all public healthcare practices that are diffused to various communities successfully, as well as those that are successful in one community with a potential for exploration elsewhere. It also captures community efforts that make adaptations successful for any number of reasons, as these can be helpful in future decisions related to adoption and diffusion. The platform has three underlying mechanisms to foster innovation. The three mechanisms foster innovation by supporting (1) information integration and knowledge coordination; (2) multi-stakeholder engagement to scout, share, and disseminate knowledge to foster innovation; and (3) servitization and productization agility to create products and processes that support innovation. These three mechanisms are discussed next.

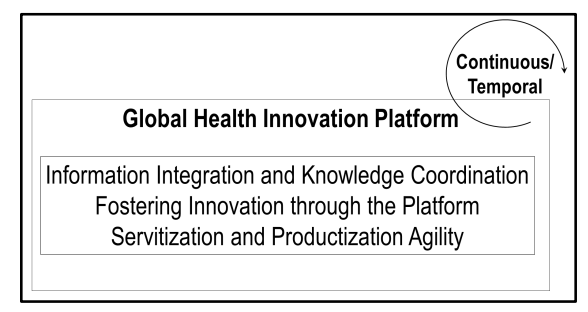

Figure 2: The Innovation Fostering Activities of a Global Health Platform

\subsection{Information integration and knowledge coordination}

When knowledge within a firm is isolated within the boundaries of a sub-unit, it hinders the capacity of an organization to recombine it in the quest for innovation [23]. Interdepartmental separation and lack of co-ordination results in poor understanding and low synchronization of the knowledge needed to develop new products [24]. Integration across organizational silos can help overcome barriers to the continuous expansion of knowledge, and such knowledge accumulation is needed to facilitate the generation of novel ideas and create new knowledge [25]. Innovation requires the creation of knowledge and the sharing of this knowledge to mobilize action towards problem solving [8], and the mechanism proposed supports such a sharing of knowledge across organizational silos. 
Similarly, the importance of access to knowledge for innovation is well recognized (e.g. [26, 27]). Access to knowledge here refers to the availability of knowledge from multiple sources to help workers within a firm improve their potential to innovate [28]. Building knowledge to support access requires the documentation of various diffusion models, contextualized by community characteristics.

GHI has both an opportunity and a capability to create a knowledge repository of healthcare practices that can be used for search and retrieval. This was illustrated with the use of the hub and spoke model to support mental health rehabilitation in the US.

\subsection{Fostering innovation through multi- stakeholder engagement}

An innovative ecosystem within an organization strives to improve links across different units, agents, and stakeholders to support alignment of two different mindsets or perspectives: an innovative mindset that is non-linear in thinking and risk-taking, and a business mindset that is methodical and somewhat risk-averse in its calculation of return on investment. A platform can act as a bridge between these two by collecting ideas, openly and/or anonymously, for consideration as a way to allow unbiased, non-linear thinking. It can then publish selected ideas and the criteria used for their support to convey a business case on risks, returns, and value. Such a clear articulation of the thinking that went into submission and selection can lead to informal discussion and continual refinement over time, thus bridging the gap between these two different mindsets. More importantly, people over time can engage in brainstorming ideas and their prioritization using a broader view of how to support a culture of innovation.

For example, those seeking grants to support public health practice diffusion may need to adopt a business mindset to articulate measurable value propositions, while those responsible for diffusing the practice into a global community need to embrace non-linear thinking and some risk-taking. Bridging these two perspectives, while a challenge, can also lead to opportunities over time if prior knowledge can be used to help either develop a new approach or evaluate the viability of an existing approach.

The individual researchers and global community practitioners can each act as consultants or observers in the exploration and diffusion process. Enabled by the platform, GHI can help bridge the differences in the perspectives each one will bring.

\subsection{Productization and servitization agility}

Dynamic capabilities theory argues that agility is a key for innovation [29]. This theory posits that dynamic capabilities are important contributors to an organization's ability to change and adapt. Innovative organizations that produce products need servitization agility (the ability of a business to adapt to changing conditions that demand services) and productization agility (the ability to use innovation-to-product architecture by creating products from services) [30]. While most product companies that want to be active in providing services will design these products for service, many service companies must convert their practice knowledge into products.

Servitization for GHI may include modularizing healthcare practices in components that can act as training modules for care providers (e.g. nurses or community health workers), mobile apps that can provide step-by-step implementation of practice knowledge, or products with embedded AI. An illustration of the last example is a medical device that draws blood and has an intelligent agent that poses questions regarding the context before blood is drawn or after for storage. The resulting knowledge repositories can lead to opportunities for creating "products" (servitization) that can have broader use and potential commercialization.

GHI can be a vehicle for such servitization and has already demonstrated it through its bootcamp program used to provide standardized training discussed in Table 2 .

In summary, GHI acts as catalyst to foster public healthcare practice diffusion by bridging the mindset of those with both linear and non-linear thinking and leverage the knowledge base in support of exploration and evaluation.

\section{Conclusion}

Lack of confidence in the quality and effectiveness of a practice that worked in a developing country and its adaptability to the US context is a major challenge in moving innovations freely across a global network. GHI addresses this challenge by evaluating innovative healthcare practices on clinical quality and effectiveness. While this evaluation is value agnostic with respect to the geographic, social, and cultural settings from within which the innovation originates, GHI has to pay particular attention to the contextual factors that both the innovation source and the recipient have in common. Using many elements GHI used in the diffusion of public health practices across the global network, the paper proposes a GHIP 
platform to support the identification of innovation types for diffusing public health practices.

Using a taxonomy for the characterization and searchability of these innovations, GHI can support dialogue, positively influence mindsets, and support both linear and non-linear thinking among multiple stakeholders to support the wider sharing of practices that have shown value. Believing that there is much more that global communities share with one another than separately define them, GHI offers GHIP as a model of equity-building in innovation diffusion, as well as a functional tool to identify opportunities for servitization of diffusion models for faster deployment in the future. We conclude by suggesting three future research directions to facilitate global value cocreation, partnerships, and improved search to nurture innovation flow.

\subsection{Opportunities for collaborative value creation}

While the current GHI model creates value through co-design of methods captured in its knowledge repository by contextualizing these to the social context, it sees potential to co-create value through collaboration. As it solicits ideas from the local community for public healthcare practices that can address a key need, it can concurrently search the knowledge base to identify practices that were diffused effectively in communities at large with similar social, economic, technical, and educational challenges. Such practices can be shared with communities it serves (e.g. Detroit) and let these communities identify their potential as well as challenges. Such a process can be reversed as well, with the global community identifying a need and the US community sharing what worked for them. This public-to-public collaboration model can be enabled by GHI and fine-turned by the various internal HFHS teams before pilot testing in the community begins. This enables HFHS to focus on the specific clinical or population health aspects of the practice, while the larger community (public) can, in collaboration with GHI, decide on its social relevance.

\subsection{Partnership for Diffusion of Practice}

GHI, using the GHIP platform, can start to build an extensive repository of innovations over the course of several years of research, training, and capacity building activities around the world. While some of these innovations can be broader in focus, GHI can narrowly define some it can lead, based on the skillset of its labor force, the leveragability of multidisciplinary relationships with medical providers and experts from across the health system, and a careful examination of the most salient health challenges in the area it serves. However, it may choose to partner with other healthcare organizations if a community decides the appropriateness of some innovations outside its focus area.

\subsection{Innovation Search Criteria}

Both collaboration and partnerships can be supported if the search criteria used to identify innovations in the knowledge repository can be expanded. At this time, the topics on which the search can be conducted include: source of innovation (where it is developed); income status of source (on some metric such as GDP); population density; religious, ethnic, racial, or demographic characteristic(s); and type of innovation. Other types of information can be added, such as who implemented the innovation; characteristic(s) of the innovation recipient or beneficiary; and contextual considerations of the source that adopted the innovation (e.g. limited transportation infrastructure, high access challenge, severe uptick of a disease, etc.). By gathering such data, innovation type search by communities can also be supported with the influencers who played a role in their implementation as well as any other value propositions, all supporting the first two phases of design for diffusion among global communities GHI serves.

\section{References}

[1] K. Kulasabanathan, H. Issa, Y. Bhatti, et al., "Do international health partnerships contribute to reverse innovation? A mixed methods study of THET-supported partnerships in the UK," Globalization and Health, 13(25), 2017.

[2] C. D. Johnson, J. Noyes, A. Haines, K. Thomas, C. Stockport, A. N. Ribas, M. Harris, "Learning from the Brazilian community health worker model in North Wales," Globalization and Health, 9 (25), 2013.

[3] A. Biganwaho, C.T. Nutt, V. Mutabazi, C. Karema, S. Nsanzimana, et. al., "Shared learning in an interconnected world: innovations to advance global health equity" Globalization and Health 9 (37), 2013.

[4] S. Kinkade, K. Verclas, "Wireless technology for social change: trends in mobile use by NGOs," United Nations Foundation-Vodaphone Group Foundation Partnership, pp. 11-22, 2008.

[5] J. Donner, "Innovations in mobile-based public health information systems in the developing world: an 
example from Rwanda," presented at: "Workshop on mobile technologies and health: benefits and risks," Colombia University Center for Global Health and Economic Development, 2004.

[6] H. Aviles, A. Belli, R. Armijos, F. P. Monroy, E. Harris, "PCR detection and identification of Leishmania parasites in clinical specimens in Ecuador: a comparison with classical diagnostic methods," Journal of Parasitology 85(2):181-7, 1999.

[7] J. G. Ruiz-Peláez, N. Charpak, L. G. Cuervo, "Kangaroo mother care, an example to follow from developing countries," BMJ, 329(7475):1179-81, 2004.

[8] J. W. Dearing, D. K. Smith, R. S. Larson, C. A. Estabrooks, "Designing for diffusion of a biomedical intervention," American Journal of Preventive Medicine, 44 (1), S70-S76, 2013.

[9] J. W. Dearing, J. G. Cox, "Diffusion of innovations theory, principles, and practice," Health Affairs, 37 (2), 2018.

[10] B. Wejnert, "Integrating models of diffusion of innovations: a conceptual framework," Annual Review of Sociology, 28(1), pp. 297-326, 2002.

[11] V. Rowthorn, A. J. Plum, J. Zervos, "Legal and regulatory barriers to reverse innovation," Annals of Global Health, 82(6), pp. 991-1000, 2016.

[12] M. Harris, E. Weisberger, D. Silver, J. Macinko, “"They hear 'Africa' and they think that there can't be any good services'- perceived context in cross-national learning: a qualitative study of barriers to reverse innovation," Globalization and Health, 11(45), 2015.

[13] E. M. Rogers, Diffusion of Innovations, 5th ed., Simon and Schuster, New York, 2003.

[14] V. Govindarajan, C. Trimble, "Reverse innovation: a global growth strategy that could pre-empt disruption at home," Strategy \& Leadership, 40(5), pp. 5-11, 2012.

[15] J. W. DePasse and P. T. Lee, "A model for "reverse innovation' in health care," Globalization and Health, $(9: 1)$, p. 40, 2013.

[16] V. Govindarajan, C. Trimble, Reverse innovation: create far from home, win everywhere, Harvard Business Press, Boston, 2012.

[17] J. W. Creswell, W. E. Hanson, V. L. Plano-Clark, \& A. Morales, "Qualitative research designs: selection and implementation, The Counseling Psychologist,35(2), pp. 236-264, 2007.

[18] World Health Organization (WHO), "Monitoring the building blocks of health systems: a handbook of indicators and their measurement strategies," WHO, 2010 .

[19] M. Harris, "Community health workers: an opportunity for reverse innovation," The Lancet, 382(9901), 1326-7, 2013.

[20] National Coalition on Homelessness, "LGBTQ homelessness," Jun 2017. Accessed September 4 at: http://nationalhomeless.org/wpcontent/uploads/2017/06/LGBTQ-Homelessness.pdf

[21] M. Uhl-Bien, R. Marion, and B. McKelvey, "Complexity leadership theory: shifting leadership from the industrial age to the knowledge era," in Leadership, Gender, and Organization, Springer, pp. 109-138, 2011.

[22] T. Dewett and G. R Jones, "The role of information technology in the organization: a review, model, and assessment," Journal of Management, 27(3), pp. 313346,2001 .

[23] R. M. Henderson and K. B. Clark, "Architectural innovation: the reconfiguration of existing product technologies and the failure of established firms," Administrative Science Quarterly, pp. 9-30, 1998.

[24] D. Dougherty, "Interpretive barriers to successful product innovation in large firms," Organization Science, 3(2), pp. 179-202, 1992.

[25] R. F. Hurley and G. T. M. Hult, "Innovation, market orientation, and organizational learning: an integration and empirical examination," The Journal of Marketing, pp. 42-54, 1998.

[26] S. L. Brown and K. M, Eisenhardt, "The Art of continuous change: linking complexity theory and timepaced evolution in relentlessly shifting organizations," Administrative Science Quarterly, pp. 1-34, 1997.

[27] I. Nonaka, "A Dynamic Theory of Organizational Knowledge Creation", Organization Science, 5(1), pp. 14-37, 1994.

[28] M. Earl, "Knowledge Management Strategies: Toward a Taxonomy", Journal of Management Information Systems, 18(1), pp. 215-233, 2001.

[29] D. J. Teece, G. Pisano, A. Shuen, "Dynamic Capabilities and Strategic Management," Strategic Management Journal, pp. 509-533, 1997.

[30] M. Krishnan, C. Prahalad, The New Age of Innovation. Driving Co-Created Value through Global Networks, McGraw-Hill Professional, 2008. 